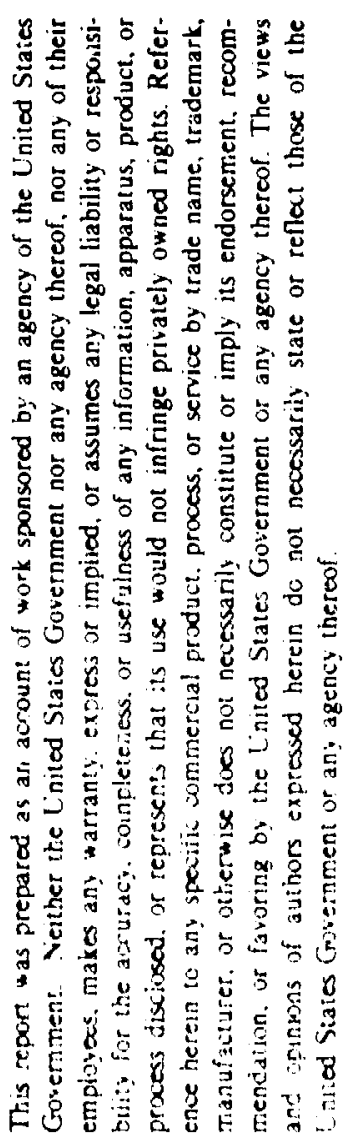

C. D. Ziomek, P. M. Denney, A. H. Regan, M. T. Lynch,

Author(s):

S. P. Jachim, L. E. Eaton, E. F. Natter

$$
\sin 04
$$

Submittod to:

1993 Particle Accelerator Conference

May 16-20, 1993

Washington, DC
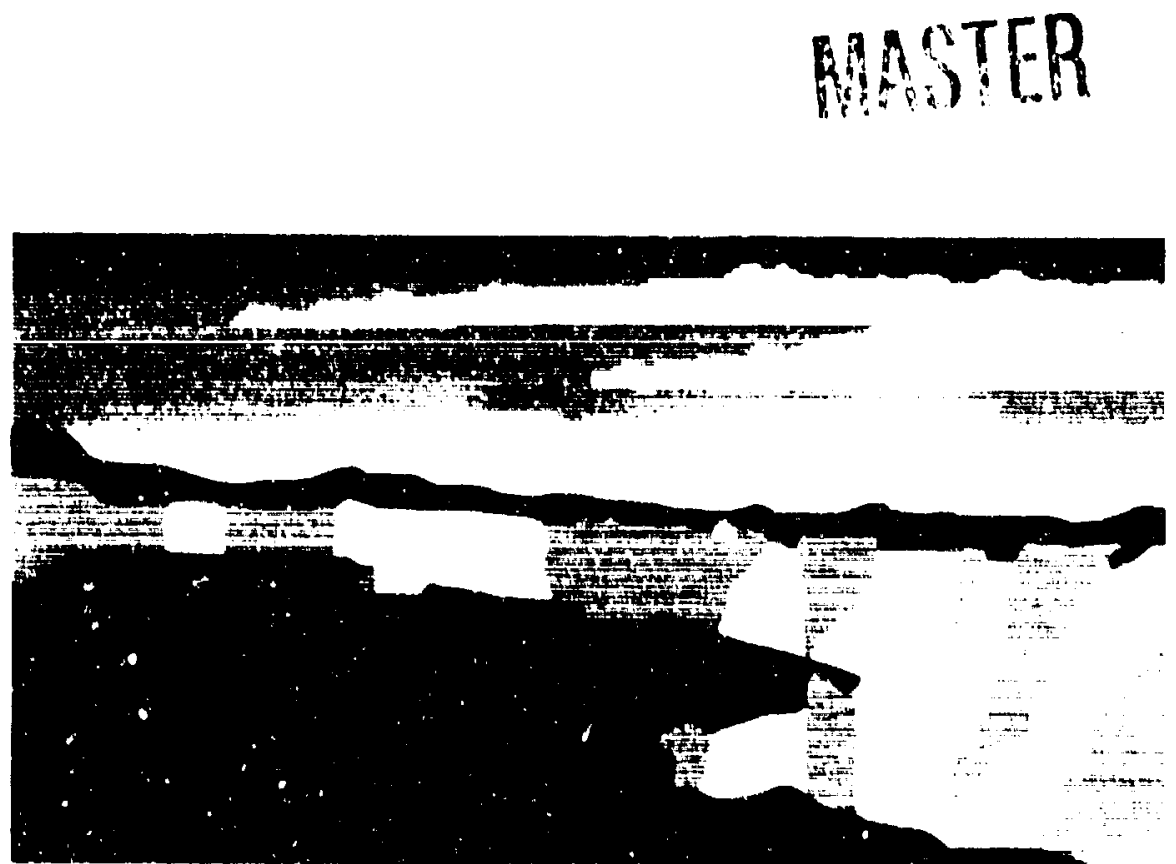

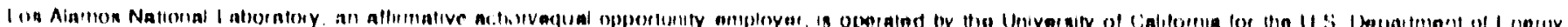

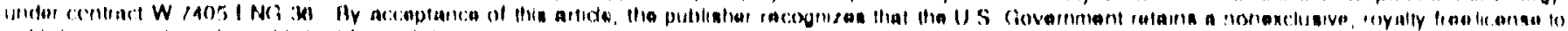

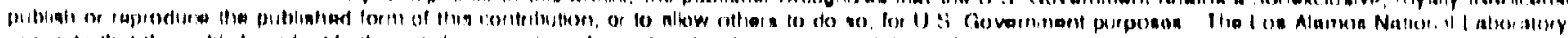

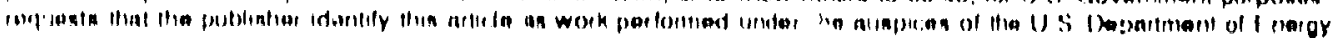




\title{
Results Of Adaptive Feedforward On GTA*
}

\author{
C. D. Ziomek, P. M. Denney, A. H. Regan, M. T. Lynch, S. P. Jachim, L. E. Eaton, E. F. Natter
}

MS-H827, Los Alamos National Laboratory, Los Alamos, NM 87545

Abstract

This paper presents the results of the adaptive feedforward system in use on the Ground Test Accelerator (GTA). The adaptive feedforward system was shown to correct repetitive, high-frequency errors in the amplitude and phase of the RF field of the pulsed accelerator. The adaptive feedforward system was designed as an augmentation to the RF field feedback control system and was able to extend the closed-loop bandwidth and disturbs nce rejection by a factor of ten. Within a second implementation, the adaptive feedforward hardware was implemented in place of the feedback control system and was shcwn to negate both beam transients and phase droop in the klystron amplifier.

\section{INTRODUCTION}

The GTA control system uses feedback to control the RF ficld in the accelerating cavities. A simplified block diagram of the GTA RF control system is depicted in figure 1.

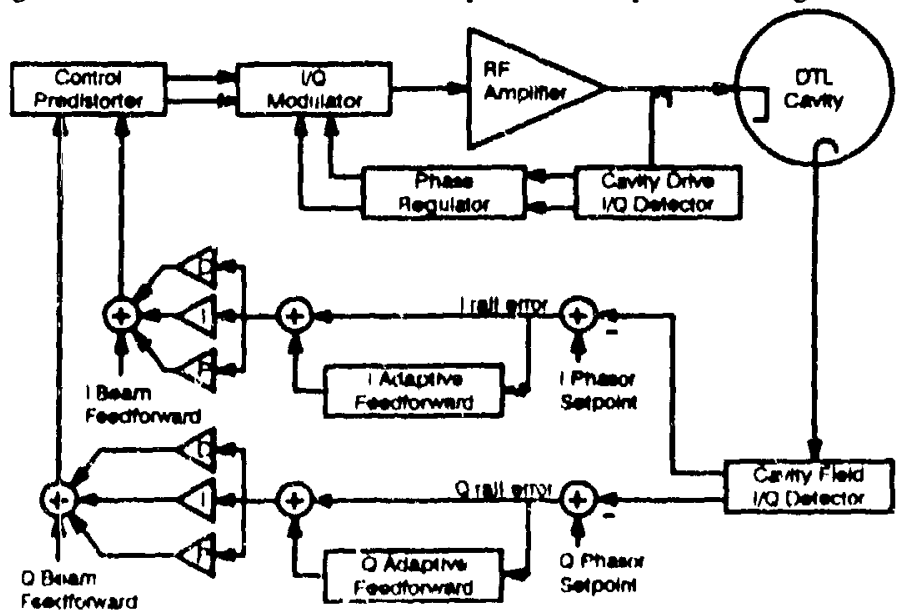

Figure 1. Simplificd blexk diagram of (iTA control system

(losed-loxop bandwidths of a few hundred kIHz have heen Jemonstrated by the (jiA RF control systems |11. These bandwidihs are limited by the physical propertics of the high ( ) cryogenic cavities. the high-power amplifier responses, and the long propagation delays cuused by the large physical distances between cyuipment. The amplitude and phate disturbances to the RF ficld that are beyond the closed lowp bandwidt cause crror in the accelerating ficld parameters. One significant crror that cxcurs with every RF pulse is the beam turn on transient. $A$ fast risetime on the beam (auses the accelerating field tu drexpl before the feculback system can compensate. Ihe heam turn on disturbance causes tamsient errors in the field amplit ude and phase for a few microseconds as the fecdlback likep recovers. 1)ue to the

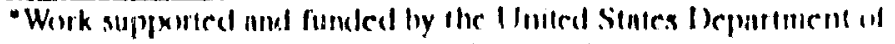

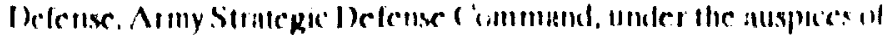
the I Inted Stules I)epautuent of linerky.
}

repetitive nature of the beam transients, the feedforward correction function can be inserted into the drive signal that will predict the beam transient affects. This correction function is adaptively updates as the accelerator operates to determine and track the optimum correction function to negate the repetitive disturbances. The detailed theory of operation is described elsewhere [2-4]. This paper will focus on the experimental results of the hardware functioning on first drift tube linac (DIL) cavity of GTA.

\section{ENHANCEMENT TO FEEDBACK}

As depicted in figure 1 , the adaptive feedforward hardware was designed to operate as a modular addition to the feedback control system. This figure shows the experimental setup for the adaptive feedforward tests on the first $850 \mathrm{MHz}$. DTI cavity of GTA. The operating conditions for the DTL were a gap voltage of $2.1 \mathrm{MV}$, a beam current of $50 \mathrm{~mA}$ with a $-30^{\circ}$ synchronous phase, and copper losses of $33 \mathrm{~kW}$. From this, the beam loading calculates to be $73 \%$.
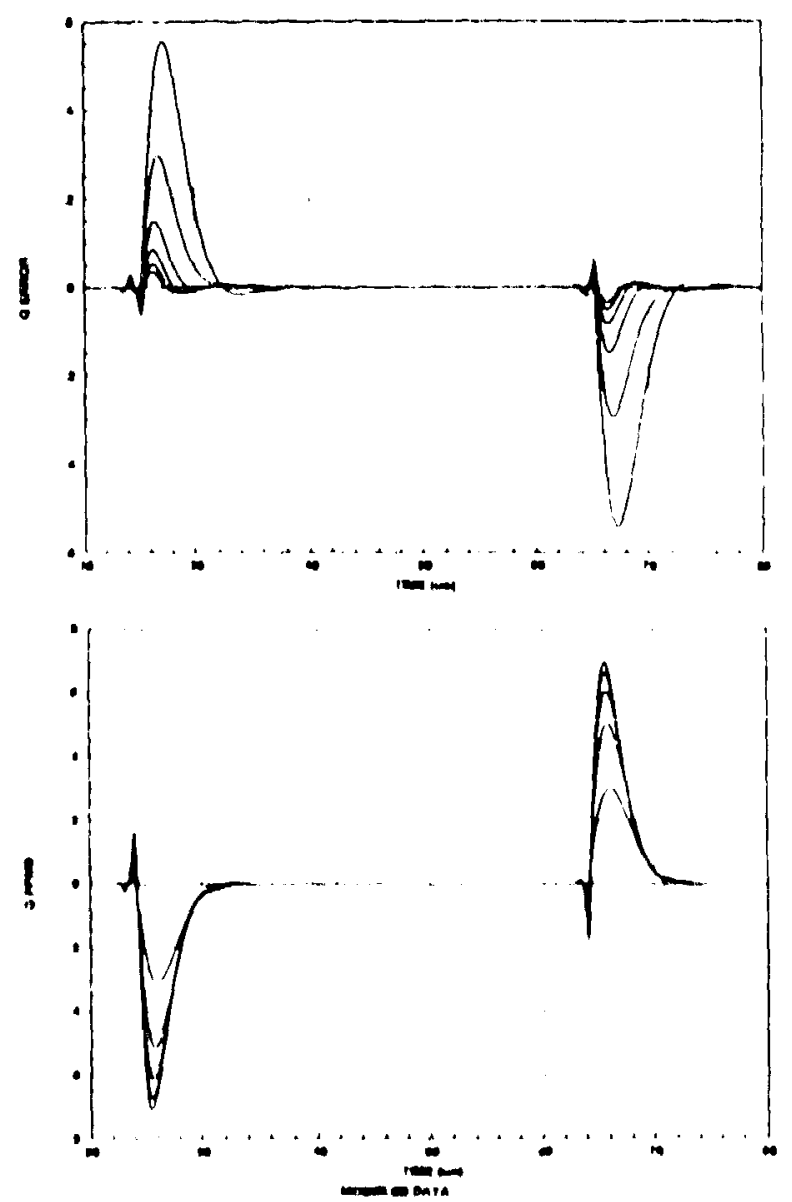

Flaure 2. Medelicd results of feedforwath as enliancencent

lighte 2 shows the expected performbinge from the

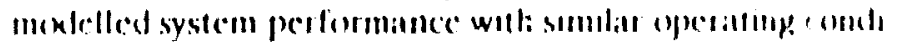


tions. This figure shows five traces that depict the feedforward adapting from zero over the course of a 50 pulses. In addition, the correspording error signals are shown to be reduced by the insertion of the correction function. These traces show the quadrature channel only, but the in-phase errors are adaptively reduced simultaneously.
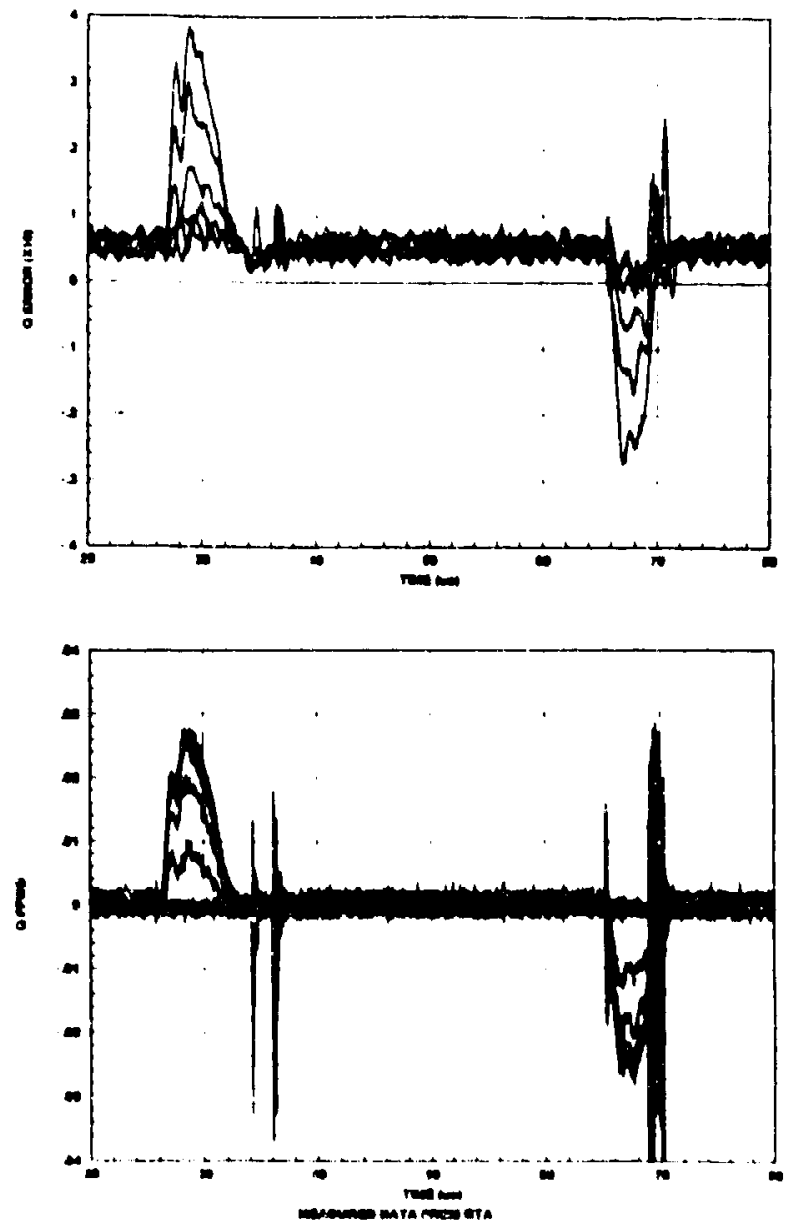

Figure 3. Measured results of fcedforward on GilA

Figure 3 shows the measured data from ti:c experiment on (;IA. Again five (races in a sequence of.$x$ ) pulses are shown. As the system operation progresses. the correction function improves and the crror signal is reduced. Nolace that the measured data clesely matches the moxlelled data. The experimental resuits in figure 3 show that a $1 \%$ error in the ficld quadrature cause ty the beam tu-n -on transient could be reduce to less than $0.015 \%$ with fecuforward.

\section{RI:U.ACING; HI:IIHAR'K}

In addition to the intenued arplementation of ahe adaptive fecedforward muxlule, a secand conifiguration for the ndaptiv: fecdforward incodule wiss evaluated. Instead of using the device as a fecdforward enhancement t.) the fecd hask comtrol system, the device an be used is an adaptive: controller, replateme the feceltack control system. Figure 4 shows the topkshgy of this comfiguration, where the control

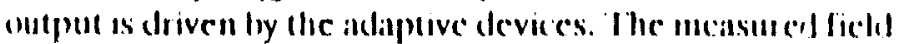

parameters are used to correct the control output as the system parameters vary over time. Any changes in the sysiem

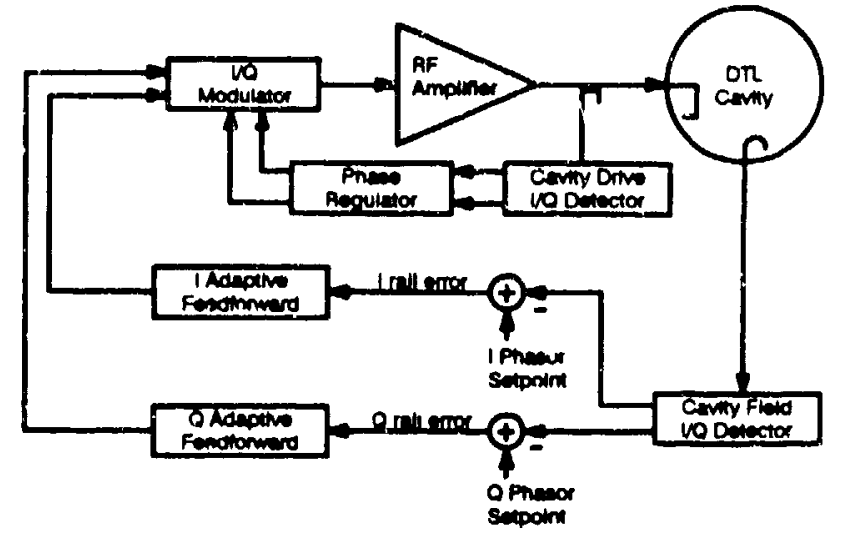

Figure 4. Diagram of control system with only feedforward

are tracked by the adaptive controllers which will track slow changes that occur over hundreds of milliseconds. With a fixed RF system configuration, the field amplitude and phase can be precisely maintained. One drawback is that the feedforward function takes a number of pulses to adaptively determine the correct control output, and while it is adaptıng. the field parameters are not held at the operating point. But once the hardware has a chance to adapt, the field amplitude and phase can be maintained at the operating point.
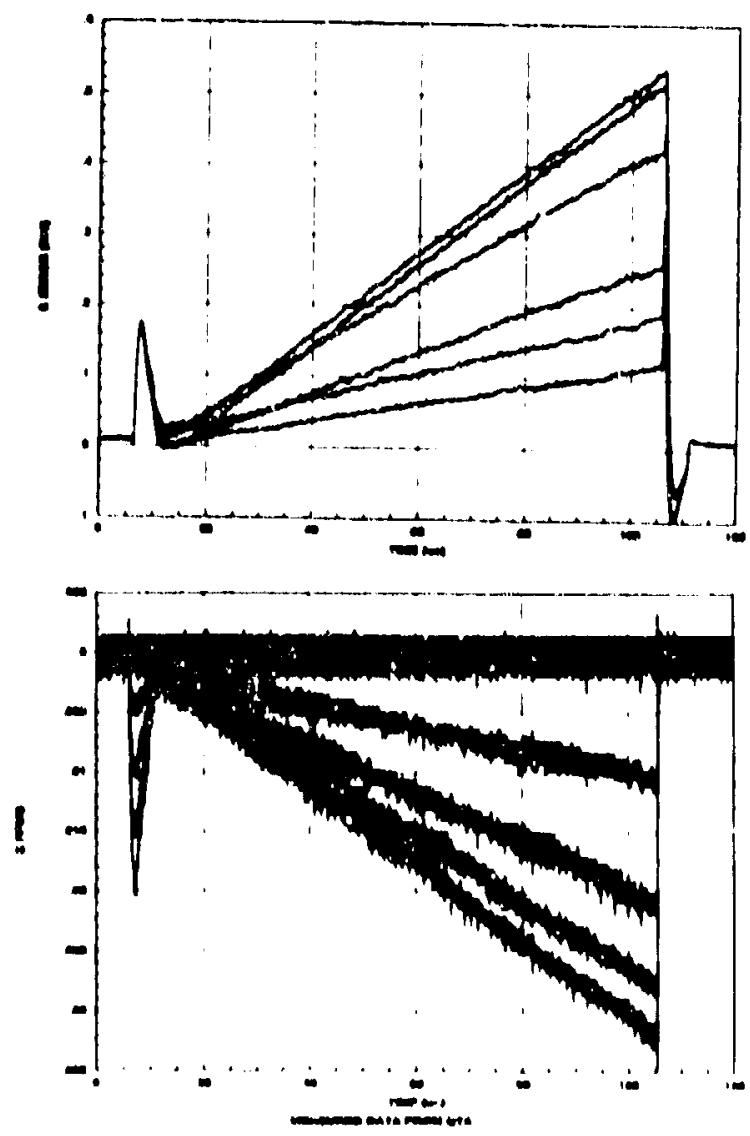

Flgute 5. Measured acsults al fecollonward unly 
Figure 5 shows the measured results of using the device as an adaptive controller to maintain the amplitude and phase of the RF field in the accelerating cavity. Any instantaneous changes in the system require a few seconds for the feedforward control function to adapt, but the sysiem does track slow changes very closely. During this experiment, the adaptive controller was able to hold the RF ficid parameters within $0.5 \%$ of the operating point for many rninutes of operation.

\section{FUIURE WORK}

These experiments proved extremely successful and verified the concept of adaptive feedforward as a viable solution to improving the field control for puised accelerators. In addition, some possibilities for additional work in the future were identified. As shown in figure 3, there are transient glitches that grow slowly as many pulses are accumulated. These glitches are a result of the adaptive algorithm used that accumulates the error functions for all past pulses with no way of eliminating some of the past data. Consequently, any circuit or computational glitches will eventually grow to become significant. Consequently, a revision that incorporates a forgetting function has been designed. The algorithm governing the adaptive proxess remains

$$
f_{N}(t)-\sum_{i=0}^{N-1} k_{i} \cdot e_{i}(t+\Delta T)
$$

but whereas in the original implementation all the $k_{i}$ values were identical, the revision incorporates exponential $k_{i}$ values, creating a forgetting function. This forgetting function provides a sliding window that is used to weight a finite number of past data values for accumulation into the correction function. Consequently the algorithm for the revision is described by the equation

$$
f_{N}(t)-g \cdot f_{N-1}(t)+k \cdot e_{N-1}(t+\Delta T) .
$$

In this algorithm, the gain, $k$, corresponds to the adaptation gain which affects the sensitivity and adaptation time for the revice. The gain, $g$. provides the forgetling function that is used to discard old data with a exponential decay. The preliminary tests with the new design show that by including the forgetting function, $g$, the adaptation gain, $k$. can be increased significantly. Thus, the new design allows more input sensitivity (more dymamic mange) and provicles a faster settling and tracking time.

The success of the adaptive controlles configuration enables the extension of this type of device to additionat applatations. An adaptive, stand alone contuller could be useful for many accelerator RI applications where conventional fecolback controll is impractical. for eximple, shomt pulse length acceleriturs typically do not have lime lor fecolbick corrections. The adiphtive controller could adap) tively predict the correct control outpute.

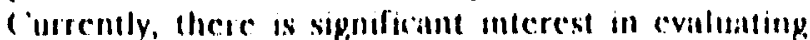
the usefulness of the current design for other acedetatton applicutions. Maptive fecolforward tests ate sebeduled for

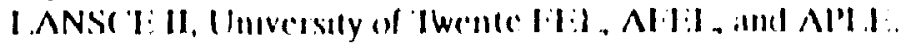

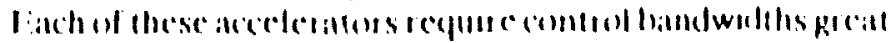

er than a feedback system can provide. The adaptive feedforward is a viable solution to this common accelerator RF demand.

\section{REFERENCES}

[1] P. Denney, S. Jachim, "Measured performance of the GTA RF Systems" Proc. IEEE Particle Accelerator Con. ference. May, 1993.

[2] C.D. Ziomek, "Adaptive feedforward in the L.ANL RF control system" Proc. Linear Accelerator Conference. August, 1992.

[3] S.P. Jachim, et. al., "The Los Alamos VXI-based modular RF conirol system," Proc. IEEE Particle Acceleraror Conference. May, 1993.

[4] C. Ziomek, S. Jachim, E. Natter, "Design of a multivariable contiol system using gain-shaping in the frequency domain," Proc. IEEE Punticle Accelerator Confurence. May, 1991. 